\title{
Pemanfaatan Sistem iJC Berbasis OJS Sebagai Media E-Journal Pada STISIP YUPPENTEK
}

\author{
Indri Handayani ${ }^{1}$ \\ Qurotul Aini', \\ Novita Sari $^{3}$ \\ Dosen STMIK Raharja $^{1,2}$, Mahasiswa STMIK Raharja ${ }^{3}$ \\ E-mail: indri@raharja.info, aini@ raharja.info ${ }^{2,}$.novita@ raharja.info ${ }^{3}$
}

\begin{abstract}
ABSTRAK
Dengan melihat kecanggihan teknologi terkini, sehingga informasi tidak lagi dalam bentuk konvensional namun sekarang sudah diterapkan elektronik yang disajikan. Di dalam pengelolaan karya ilmiah di STISIP YUPPENTEK ini masih manual sehingga memiliki permasalahan-permaslahan seperti penerbitan jurnal yang begitu susah dan data terpisah-pisah karena membutuhkan waktu cukup lama dan biaya cukup besar. Arikel ilmiah pada STISIP YUPPENTEK belum memenuhi syarat ketentuan dikti perihal akreditasi jurnal yang mengharuskan jurnal dikelola dengan cara online dalam pengelolaan yang dilakukan lebih dengan mudah dan cepat. Setelah peneliti menganalisa permasalahan dengan menggunakan suatu metode pengumpulan data berupa observasi, wawancara dan studi pustaka serta menggunakan UML (Unified Modeling Language). Untuk mengatasi permasalahan tersebut peneliti memberikan usulan sistem yang memudakan pengguna sehingga proses pengelolaan jurnal dapat lebih memudahkan pengguna.
\end{abstract}

Kata Kunci: Jurnal Ilmiah, E-Journal, Open Journal System, Indeksasi

\begin{abstract}
By looking at the sophistication of the latest technology, so the information is no longer in the conventional form but now it is applied electronics are presented. In the management of scientific work in STISIP YUPPENTEK is still manual so it has problems such as publishing journals that are so difficult and data separated because it takes quite a long time and cost is quite large. The scientific article on STISIP YUPPENTEK has not fulfilled the requirement of dictation about journaling accreditation which requires the journal to be managed by online in the management which done more easily and quickly. After the researchers analyze the problem by using a method of collecting data in the form of observation, interview and literature study and using Flowchart. To overcome these problems the researchers provide a system proposal that allows users so that the process of managing the journal can further facilitate the user.
\end{abstract}

Keywords: Scientific Journal, E-Journal, Open Journal System, Indexation

\section{PENDAHULUAN}

Dengan melihat kecanggihan teknologi terkini, sehingga saat ini informasi tidak lagi

94 | Indri, Qurotul, Novita - Pemanfaatan Sistem iJC Berbasis OJS Sebagai.... 
disediakan dalam bentuk konvensional atau tercetak namun disajikan sudah dalam bentuk online. Perguruan Tinggi merupakan sebuah bidang teknologi yang dipengaruhi okleh perkembangan zaman. Perkembangan zaman yang sudah semakin meningkat mendukung keinginan untuk selalu menyediakan berbagai bentuk layanan yang mempermudah bagi penggunanya sehingga diakses lebih dengan mudah dan cepat. Dalam publikasi suatu karya ilmiah hal ini pada dasarnya melibatkan banyak proses yang dilakukan, artikel ilmiah membutuhkan beberapa proses sehingga suatu jurnal dapat dikatakan layak dipublikasikan menurut ketentuan yaitu diantaranya dari proses review artikel, dilanjutkan pengiriman suatu revisi (Jika jurnalperlu ada yang diperbaiki), dan proses editoring sampai akhirnya sebuah karya ilmiah dapat diterbitkan kedalam sebuah jurnal.

Pada dasarnya sebuah jurnal merupakan suatu terbitan secara berkala untuk menyajikan berbagai jenis informasi yang ilmiah dalam sebuah bidang ilmu pengetahuan. Penyajian jurnal sebelum era digital yaitu masih manual dan konvensional seperti halnya sebuah buku. Sehingga, hal tersebut dikatakan bahwa asal mulanya sebuah jurnal belum memiliki berbagai macam varian dengan model lain dalam hal sebuah bentuk penyajiannya. Dengan semakin banyaknya jumlah penduduk yang minat untuk belajar ilmu sosial dan ilmu politik di kota tangerang, maka ada beberapa pihak mendirikan sebuah kampus yang dikhususkan untuk mempelajari ilmu sosial dan ilmu politik, salah satunya adalah STISIP YUPPENTEK.

STISIP YUPPENTEK merupakan perguruan tinggi yang berada di kota tangerang yang mengkhususkan pada pendidikan ilmu sosial dan ilmu politik. iLearning journal center adalah istilah dari sebuah pengelolaan dan penerbitan jurnal berbasis Open Journal System (OJS) yang dikembangkan oleh Public Knowledge Project (PKP) secara open source (yang dapat dikembangkan oleh siapa saja) yang mana sistem ini dibuat khusus dapat mengelola jurnal electronik atau e-journal. Yang untuk saat ini tujuan utamanya dari sistem ini adalah untuk memfasilitasi civitas akademika STISIP YUPPENTEK agar bisa mempublikasikan setiap jurnal ilmiah yang dibuatnya secara online.

Publikasi suatu karya ilmiah dalam hal ini jurnal pada dasarnya melibatkan banyak proses dan peran yang terlibat, dibutuhkan beberapa proses hingga suatu jurnal dapat layak dipublikasi, diantaranya mulai dari proses penyerahan naskah, seleksi awal, review artikel, pengiriman revisi, (jika ada yang perlu diperbaiki), dan editoring hingga akhirnya sebuah artikel ilmiah dapat layak .diterbitkan kedalam sebuah jurnal. Dikutip dari wikipedia Sekolah Tinggi Ilmu Sosial dan Ilmu Politik Yuppentek (STISIP YUPPENTEK) adalah sebuah Perguruan Tinggi (PT) bagi umum dan operatur pemerintah yang bermaksud untuk meningkatkan kompetensinya dalam bidang teori dan praktik Ilmu Pemerintahan dan Administrasi Bisnis. STISIP YUPPENTEK Tangerang selalu konsisten dalam melaksanakan komitmen untuk menjadi Center of Exellence dalam bidang Ilmu Pemerintahan dan Administrasi Bisnis dengan tetap menjaga kualitas lulusannya. 


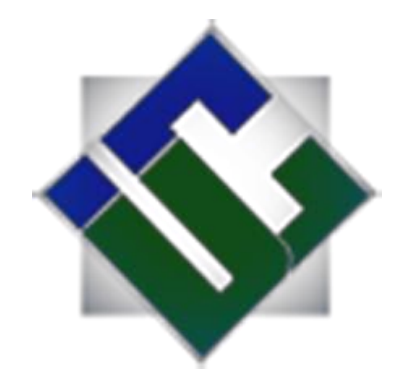

Gambar 1. Logo iJC (iLearning Journal Center)

Sumber : journal.ilearning.co

Menurut Maulana Sani (2015) iLearning Journal Center (iJC) adalah nama sebuah sistem pengelolaan dan penerbitan jurnal berbasis (yang juga merupakan nama komunitas pengelolanya) Open Journal System (OJS) yang dikembangkan Public Knowledge Project (PKP) secara open source yang dialokasikan untuk dapat mengelola jurnal elektronik atau e-journal komunitas ilearning yang untuk saat ini tujuan utamanya adalah untuk dapat memfasilitasi mahasiswa Perguruan Tinggi Raharja agar dapat menyalurkan artikel ilmiah buatannya dalam rangka memenuhi penialaian objektif.

\section{METODE PENELITIAN}

\subsection{Metode Pengumpulan Data}

1. Metode Observasi (pengamatan)

Metode Observasi ini lakukan dengan datang langsung ditempat penelitian atau pengamatan dilakukan dalam berbagai hal melihat permasalahan yang terjai didalam STISIP YUPPENTTEK dan pada objek yang diteliti sehingga penelitian dapat lebih mudah mendapatkan informasi dan meminta data-data yang dibutuhkan peneliti sebagai bahan untuk menulis laporan penelitian. Kemudian dalam sebuah penelitian diadakan sebuah pengamatan terhadap sistem yang dikembangkan

2. Metode Wawancara

Metode yang dilakukan ini dengan cara melakukan tanya jawab dengan seseorang atau beberapa narasumber secara langsung pada STISIP YUPPENTEK. Metode ini dilakukan guna mendapatkan data-data informasi yang lebih detail mengenai objek yang sedang diteliti sehingga dapat memperkuat data sebelumnya saat melakukan penelitian secara langsung.

\section{Studi Pustaka}

Selain peneliti melakukan observasi dan wawancara peneliti juga melakukan penggumpulan data menggunakan Studi Pustaka sebagai referensi penelitian. Sehingga peneliti berusaha melengkapi semua data-data yang didapatkan dengan membaca buiku atau literatur yang ada. Peneliti melakukan Studi Pustaka melalui 
sumber apa saja yang berkaitan dengan judul yang diajukan dalam sebuah penelitian untuk membantu penganalisa dan sebagai acuan yang dilakukan.

\subsection{Metode Perancangan Sistem}

Metode perancangan yang digunakan dalam meneliti adalah metode atau tata-cara yang digunakan peneliti dalam merancang sistem yang ditelitinya, dimana semua penelitian ini menggunakan metode perancangan sistem yang digunakan adalah metode perancangan flowchart untuk melengkapi analisa pada penelitian ini.

\subsection{Literature review}

Penelitian yang sudah dilakukan sebelumnya mengenai survey secara online dan penelitian lain yang berkaitan. Dalam mengembangkan dan upaya menyempurnakan sistem e-journal ini maka diperlukan melakukan studi pustaka (literature review) sebagai salah satu dari penerapan metode penelitian yang akan dilakukan. Terdapat 10 (Sepuluh) point diantaranya yaitu:

1. Penelitian dilakukan oleh Syamsul Alam. (2015) yang berjudul 'Penulisan Artikel Ilmiah Untuk Publikasi Ilmiah Melalui Jurnal". Penelitian ini dilakukan sebagai tindak lanjut dalam kegiatan ilmiah berupa penelitian atau sebuah kajian referensi sebagai alat untuk menyebarluaskan suatu hasil karya ilmiah. [4]

2. Penelitian dilakukan oleh Indri Handayani, Qurotul Aini, Fanni Oktaviani. (2016) yang berjudul "PENERAPAN SISTEM VALIDASI JURNAL DI PESSTA+ SEBAGAI PENILAIAN ARTIKEL ILMIAH DALAM MENDUKUNG KEGIATAN CIVITAS AKADEMIKA". Pada penelitian ini sebuah sistem PESSTA+ sehingga memudahkan dalam validasi jurnal untuk mahasiswa maupun mahasiswi sehingga lebih memudahkan dalam mendapatkan suatu nilai yang valid sebagai syarat kelulusan pada perguruan tinggi raharja. [5]

3. Penelitian dilakukan oleh Indri Handayani. (2015) yang berjudul "Pemanfaatan Sistem iMe (iLearning Media) dan Rinfo (Raharja. info) dalam penerapan Sistem E-Journal di CCIT Journal Pada Perguruan Tinggi Raharja". Pada penelitian ini sebuah sistem e-journal dapat mengotomatiskan dalam pengiriman artikel ilmiah sehingga pengelolaan ejournal dapat dilakukan proses tersebut dengan cepat dan efisien. [6]

4. Penelitian dilakukan oleh Andi Murniati. (2012) yang berjudul "Pemanfaatan e-journal dan ebookoleh mahasiswa di lingkungan Fakultas Tarbiyah dan Keguruan UIN SUSK Riau". Penelitian ini dilakukan untuk 
mengetahui pemanfaatan e-journal dan e-book dikalangan mahasiswa yang ada di Fakultas Tarbiyah dan Keguruan UIN SUSKA RIAU. [7]

5. Penelitian dilakukan oleh Multi Baihaqi dan Ahmad Hanafi (2015) yang berjudul "PERANCANGAN DAN PEMBUATAN E-JOURNAL MENGGUNAKAN OPEN JOURNAL SYSTEM DI STMIK JENDERAL ACHMAD YANI YOGYAKARTA" Penelitian dilakukan untuk sebuah sistem e-journal yang memberikan layanan lebih baik dan mudah diakses secara lebih luas kepada semua kontributor jurnal Telkomnika di STMIK Jendral Achmad Yani Yogyakarta.[8]

6. Penelitian yang dilakukan Hendra Darmawan Purnama Rasmaja pada tahun 2013 dengan judul “ Aplikasi Pengindeks Jurnal Online Dengan Metadata Open Archive Initiative Studi Kasus Open Journal System (OJS)” . Penelitian ini dilakukan dalam rangka mempermudah dalam mencari sebuah informasi, dimana informasi tersebut terdapat pada sebuah metadata, berbagai metadata pada beberapa aplikasi web dapate mempersulit dalam pengumpulan data. Adapun hasil dari penelitian ini yaitu aplikasi pengindeksan jurnal online yang dihasilkan sebanyak tujuh jurnal dari tiga ratus lebih paper.

7. Penelitian yang dilakukan Nizar Abdillah Alim pada tahun 2013 dengan judul “ Perancangan Elektronik Journal Bagi Dosen Dan Mahasiswa Universitas Muhammadiyah Ponorogo" . Penelitian ini dilakukan dalam rangka memudahkan mahasiswa ataupun dosen yang ingin menerbitkan jurnal karya ilmiahnya ke public, sehingga tidak perlu lagi melakukan proses seperti pengumuman permintaan tulisan, pengiriman dari penulis, review, pemberitahuan hasil review, pengiriman perbaikan tulisan, pengeditan dan layout, pencetakan hingga distribusi dilakukan secara konvensional melainkan sudah online.

8. Penelitian yang dilakukan Yuliana Ramawati pada tahun 2013 dengan judul Pengelolaan Jurnal Menggunakan Perangkat Lunak Open Journal System (OJS) di Perpustakaan Fakultas Hukum Universitas Gadjah Mada Yogyakarta" . Penelitian ini dilakukan dalam rangka mempermudah pengelolaan perpustakaan terutama pengelolaan terbitan berkala khususnya jurnal dan mempermudah user / pengguna untuk mendapatkan informasi kembali yang dibutuhkan terkait mengenai jurnal yang dicari.

9. Penelitian yang dilakukan Herny Februariyanti dan Eri Zuliarso pada tahun 2012 dengan judul "Rancang Bangun Sistem Perpustakaan untuk Jurnal Elektronik" Penelitian ini ini dibangun sebagai Sistem Perpustakaan Digital Jurnal Elektronik sehingga dapat dengan mudah diakses oleh pembaca. Sistem dapat melakukan perambaan (crawler) dari halaman web. Dari proses perambaan (crawler) ini kemudian akan diunggah. Dimana jurnal elektronik yang diunggah sudah dibuat dengan format PDF. Sistem 
Perpustakaan Digital hanya dapat diakses lokal di lingkungan Universitas Stikubank Semarang.[11]

10. Penelitian yang dilakukan oleh Mufti baihaqi dan Ahmad Hanafi pada tahun 2015 dengan judul "Perancangan Dan Pembuatan E-journal Menggunakan Open Journal System Di Stmik Jenderal Achmad Yani Yogyakarta". Pada penelitian ini dijelaskan tentang sebuah perancangan dan pembuatan sistem pengelolaan jurnal elektronik digunakan berbasis Open Journal System dalam rangka menyelesaikan permasalahan yang ada pada sistem pengelolaan jurnal yang ada pada STMIK Jendral Achmad yani Yogyakarta dimana sistem pada sebelumnya merupakan sistem pengelolaan jurnal yang dilakukan secara tercetak atau manual. Kemudian dari hasil penelitian yang dilakukan terdapat sebuah kesimpulan dimana sistem pengelolaan jurnal yang dirancang dapat bekerja sesuai dengan kebutuhan pengelolaan dan penerbitan e-journal yang terindentifikasi dalam penelitian.[12]

\section{HASIL DAN PEMBAHASAN}

Karya ilmiah merupakan suatu proses hasil karya dengan proses analisa terhadap permasalahan dan membandingkan suatu permasalahan yang ada dengan permasalahan lain untuk mendapatkan sebuah argumentasi terhadap karya yang akan dihasilkan. Jurnal merupakan suatu terbitan berseri yang berbentuk dari suatu majalah yang berisikan informasi ilmiah mengenai suatu penemuan karya mutakhir dalam kajian ilmu pengetahuan. Pada dasarnya, jurnal terbagi menjadi dua macam yaitu jurnal cetak (konvensional) dan jurnal non cetak (jurnal elektronik), namun sejalan dengan kemajuan suatu teknologi dan informasi, sehingga jurnal beraneka ragam macamnya. Dari sebuah jurnal yang diterbitkan dalam bentuk cetak dan juga ada jurnal yang diterbitkan dalam bentuk elektronik. Dengan mengikuti perkembangan informasi yang pesat, perguruan tinggi sebagai pengelola informasi diharuskan untuk beradaptasi dalam perkembangan yang sedang terjadi. Dalam subjek sebuah pencarian informasi sangat membutuhkan informasi secara lebih cepat, lebih hemat waktu, serta hemat biaya dan tenaga.

iLearning Journal Center (iJC) adalah istilah dari sebuah sistem pengelolaan dan penerbitan journal bebasis web dengan menggunakan plugin Open Journal System (OJS) yang dikembangkan Public Knowledge Project (PKP) secara open source (yang dapat dikembangkan oleh siapa saja) yang mana sistem ini dibuat khusus dapat mengelola jurnal electronik atau e-journal. Yang untuk saat ini tujuan utamanya dari sistem ini adalah untuk memfasilitasi civitas akademika STISIP YUPPENTEK agar bisa mempublikasikan setiap jurnal ilmiah yang dibuatnya secara terbuka.

Penerapan pengelolaan data jurnal yang dilakukan di STISIP YUPPENTEK masih menggunakan sistem manual. Hal ini dapat dilihat dalam keluaran yang telah dihasilkan dari proses jurnal ini yaitu jurnal cetak. Selain keluaran yang masih bersifat 
cetak atau print yang diterapkan dalam mengelola jurnal juga dirasa kurang efektif dan efisien. Mulai dari prosedur penyerahan naskah yang cukup rumit dan mesti datang ke STISIP YUPPENTEK.

\section{Use Case Diagram Sistem Yang Diusulkan}

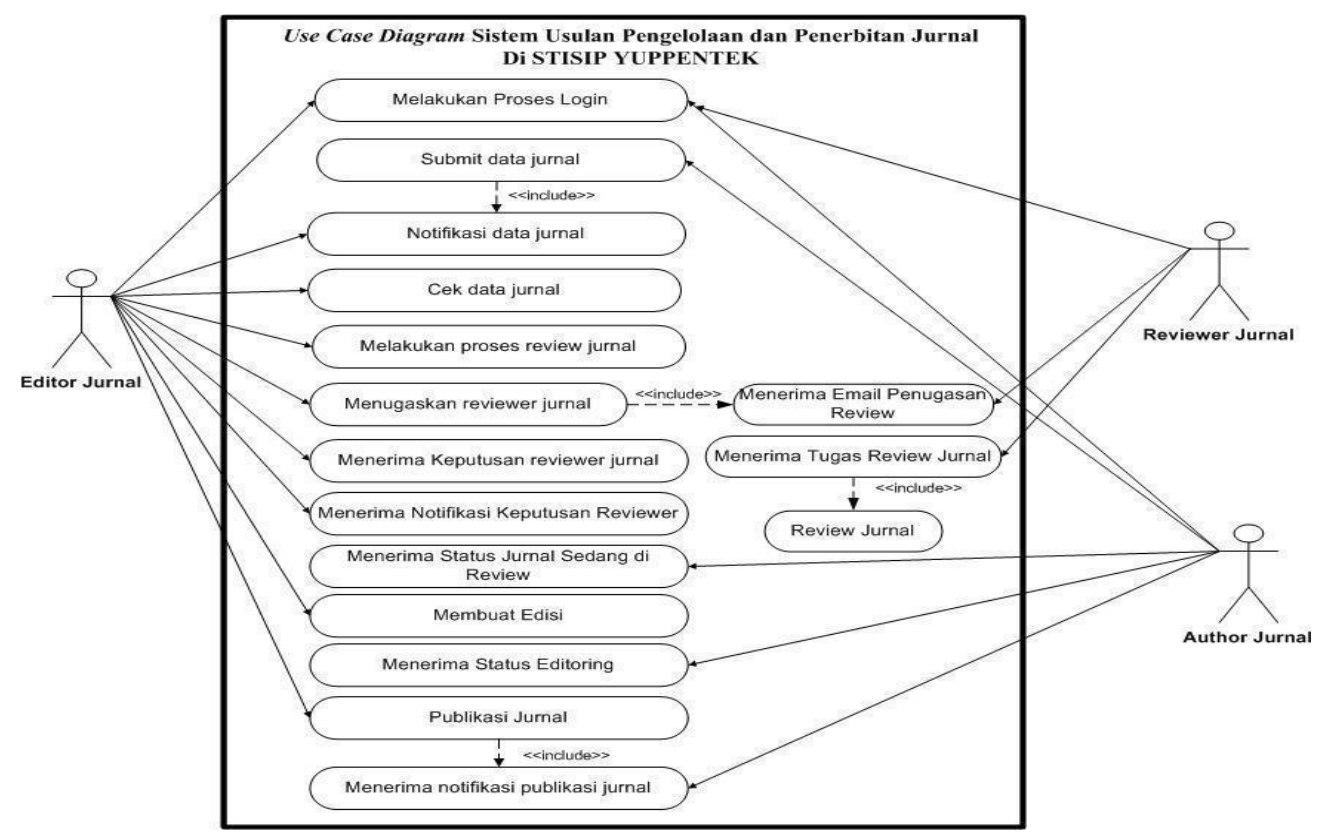

Gambar 2. Use Case Diagram Sistem Yang Diusulkan

Pada Gambar 3 : terdapat 3 actor yaitu editor jurnal, reviewer jurnal dan author jurnal. Untuk menjelaskan Use case diagram pada gambar 4.1, digunakan Use Case Glossary dan Actor Glossary yang menjelaskan deskripsi secara singkat use case yang sudah ditentukan. Selain itu use case glossary dan actor glossary juga dapat menjelaskan prosedur sistem yang diusulkan.

\section{a. Actor Glossary}

Tabel 1. Actor Glossary

\begin{tabular}{|l|l|l|}
\hline No & \multicolumn{1}{|c|}{ Aktor } & \multicolumn{1}{|c|}{ Deskripsi } \\
\hline 1 & Editor Jurnal & $\begin{array}{l}\text { Pengguna yang mempunya hak akses untuk } \\
\text { mengelolah data jurnal secara keseluruhan }\end{array}$ \\
\hline 2 & Reviewer Jurnal & $\begin{array}{l}\text { Pengguna yang mempunyai hak akses untuk } \\
\text { mereview jurnal yang ada }\end{array}$ \\
\hline 3 & Author Jurnal & $\begin{array}{l}\text { Pengguna yang mempunyai hak akses untuk membuat } \\
\text { data jurnal dan submit data jurnal }\end{array}$ \\
\hline
\end{tabular}




\section{b. UseCase Glossary}

Tabel 2. Use Case Glossary

\begin{tabular}{|c|c|c|}
\hline No & Use Case & Deskripsi \\
\hline 1 & $\begin{array}{l}\text { Melakukan proses } \\
\text { login }\end{array}$ & $\begin{array}{l}\text { Pengguna yang akan menge lolah data jurnal harus } \\
\text { melalui proses login yaitu dengan memasukan } \\
\text { username dan password }\end{array}$ \\
\hline 2 & Submit data jurnal & $\begin{array}{l}\text { Pengguna yang akan jurnalnya dipublikasi harus } \\
\text { pertama sekali melakukan proses submit data } \\
\text { jurnal }\end{array}$ \\
\hline 3 & Notifikasi data jurnal & $\begin{array}{l}\text { Memberikan informasi data jurnal kepihak editor } \\
\text { jurnal, bila ada jurnal yang baru di submit }\end{array}$ \\
\hline 4 & Cek data jurnal & $\begin{array}{l}\text { Editor melakukan pengecekan data jurnal, apakah } \\
\text { sudah masuk ke sistem atau belum }\end{array}$ \\
\hline 5 & $\begin{array}{l}\text { Melakukan proses } \\
\text { reveiew jurnal }\end{array}$ & $\begin{array}{l}\text { Editor melakukan proses review terhadap jurnal } \\
\text { sementara, sebelum diberikan ke reviewer }\end{array}$ \\
\hline 6 & $\begin{array}{l}\text { Menugaskan } \\
\text { reviewer jurnal }\end{array}$ & $\begin{array}{l}\text { Editr menunjuk salah satu reviewer jurnal untuk } \\
\text { melakukan review terhadap jurnal yang diterima }\end{array}$ \\
\hline 7 & $\begin{array}{l}\text { Menerima email } \\
\text { penugasan }\end{array}$ & $\begin{array}{l}\text { Pihak reviewer yang telah ditunjuk untuk } \\
\text { mereview data jurnal akan mendapatkan notifikasi } \\
\text { email penugasan }\end{array}$ \\
\hline 8 & $\begin{array}{l}\text { Menerima tugas } \\
\text { review jurnal }\end{array}$ & $\begin{array}{l}\text { Reviewer akan menerima tugas review jurnal yang } \\
\text { telah diberikan oleh editor }\end{array}$ \\
\hline 9 & Review jurnal & $\begin{array}{l}\text { Reviewer akan segera melakukan proses review } \\
\text { jurnal }\end{array}$ \\
\hline 10 & $\begin{array}{l}\text { Menerima keputusan } \\
\text { reviewer jurnal }\end{array}$ & $\begin{array}{l}\text { Pihak editor akan menerima hasil review jurnal } \\
\text { dari reviewer jurnal }\end{array}$ \\
\hline 11 & $\begin{array}{l}\text { Menerima keputusan } \\
\text { review jurnal }\end{array}$ & $\begin{array}{l}\text { Pihak editor akan menerima hasil keputusan } \\
\text { review jurnal baik itu diterima, ditolak ataupun } \\
\text { direvisi }\end{array}$ \\
\hline 12 & $\begin{array}{l}\text { Menerima notifikasi } \\
\text { keputusan reviewer }\end{array}$ & $\begin{array}{l}\text { Pihak editor akan menerima pesan atau informasi } \\
\text { mengenai keputusan review terhadap jurnal }\end{array}$ \\
\hline 13 & $\begin{array}{l}\text { Menerima status } \\
\text { jurnal sedang di } \\
\text { review }\end{array}$ & $\begin{array}{l}\text { Pihak author jurnal akan menerima status jurnal } \\
\text { yang telah direview oleh reviewer jurnal }\end{array}$ \\
\hline 14 & Membuat Edisi & $\begin{array}{l}\text { Pihak editor jurnal akan membuat edisi jurnal } \\
\text { yang telah lulus review jurnal }\end{array}$ \\
\hline 15 & $\begin{array}{l}\text { Menerima status } \\
\text { editoring }\end{array}$ & $\begin{array}{l}\text { Pihak author jurnal akan menerima status } \\
\text { editoring jurnal yang telah dilakukan }\end{array}$ \\
\hline
\end{tabular}




\begin{tabular}{|l|l|l|}
\hline 16 & Publikasi jurnal & $\begin{array}{l}\text { Pihak editor jurnal akan melakukan proses } \\
\text { pubilkasi terhadap jurnal yang telah lulus review } \\
\text { dan dan telah melakukan proses edisi jurnal }\end{array}$ \\
\hline 17 & $\begin{array}{l}\text { Menerima notifikasi } \\
\text { publikasi jurnal }\end{array}$ & $\begin{array}{l}\text { Pihak author jurnal akan menerima pesan } \\
\text { notifikasi terhadap publikasi jurnal yang } \\
\text { dilakukan }\end{array}$ \\
\hline
\end{tabular}

\subsection{Implementasi Program}

\subsubsection{Tampilan Menu awal}

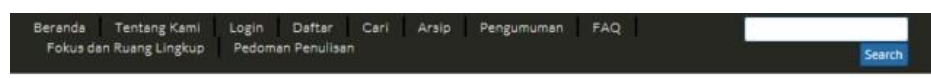

Jurnal MoZaik

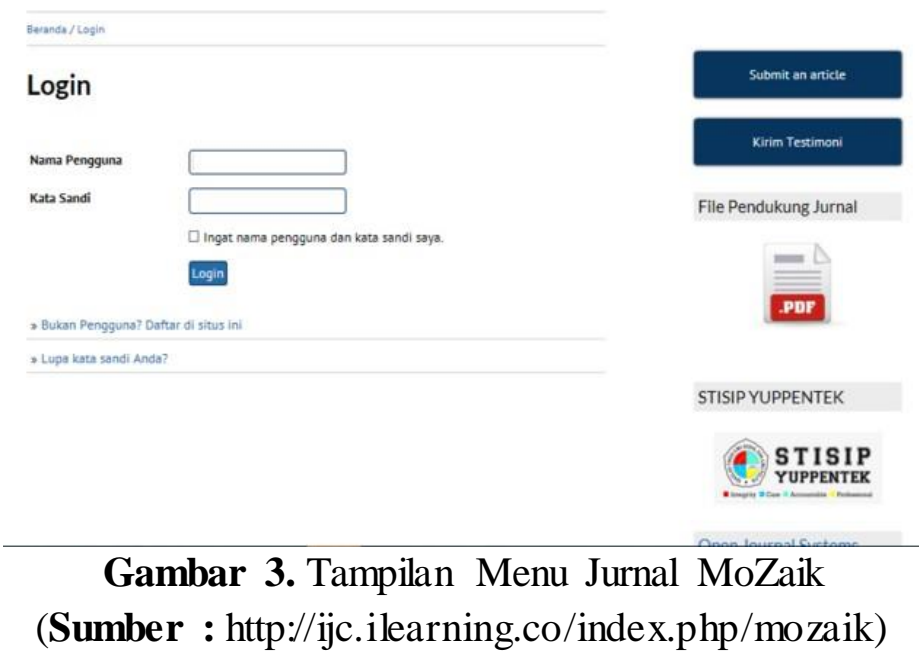

Pada gambar 3 berikut merupakan tampilan dari Halaman form login yang dapat diakses pada menu login halaman awal Jurnal Mozaik, pada bagian ini pada dasarnya sama dengan halaman form login pada umumnya yaitu tedapat field nama pengguna dan kata sandi, serta check box untuk mengingat nama pengguna dan kata sandi, serta terdapat juga alat bantu seperti petunjuk jika Pengguna belum memiliki akun dan jika Pengguna lupa kata sandi yang dimilikinya.

\subsubsection{Tampilan Menu Daftar}




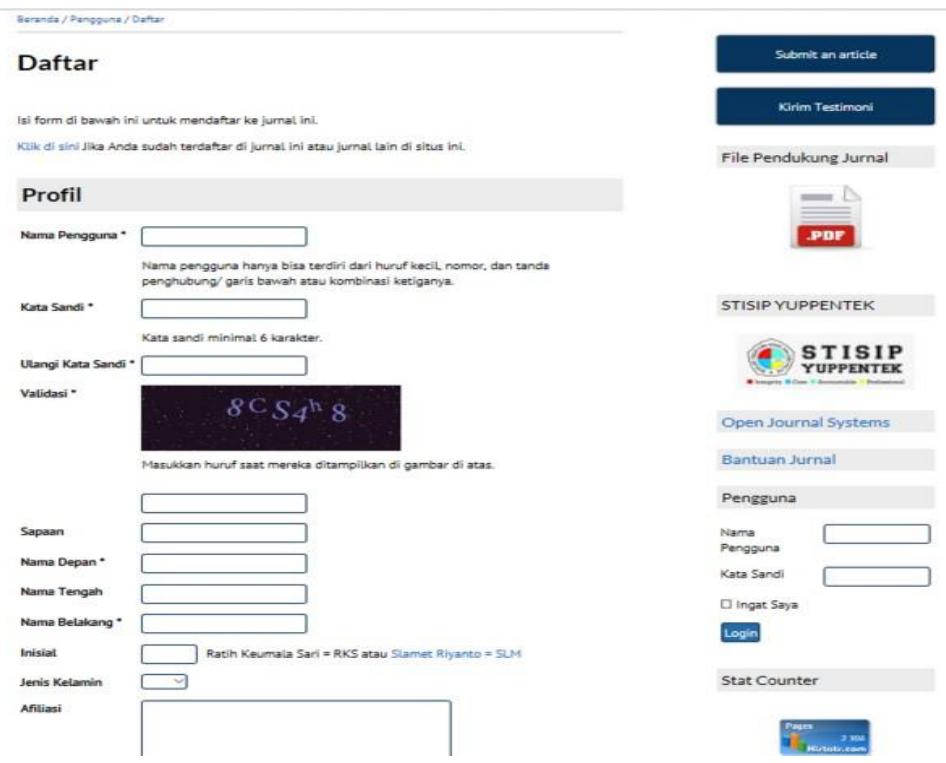

Gambar 4. Tampilan Menu Daftar

(Sumber : http://ijc.ilearning.co/index.php/mozaik/daftar)

Pada gambar 4 berikut merupakan tampilan dari form daftar akun yang dapat diakses melalui menu Daftar pada navbar halaman awal Jurnal Mozaik. Pada form ini pengguna diharuskan mengisi form yang ada khususnya yang memiliki tanda (*) wajib untuk diisi, diantaranya yaitu, Nama Pengguna, Kata sandi, Verifikasi kata sandi, Validasi CAPTCHA, nama Depan, Nama Belakang, Email, dan Konfirmasi email, kemudian pada bagian bawah form Pengguna diharuskan mengsi check box yang disediakan dimana Penulis untuk mendaftarkan akun sebagai Penulis atau Auhtor, Pembaca untuk hak akses sebagai Pembaca dan Kirimi email untuk mengirimkan salinan username dan password ke email yang didaftarkan.

\subsubsection{Tampilan Menu Tentang Kami}

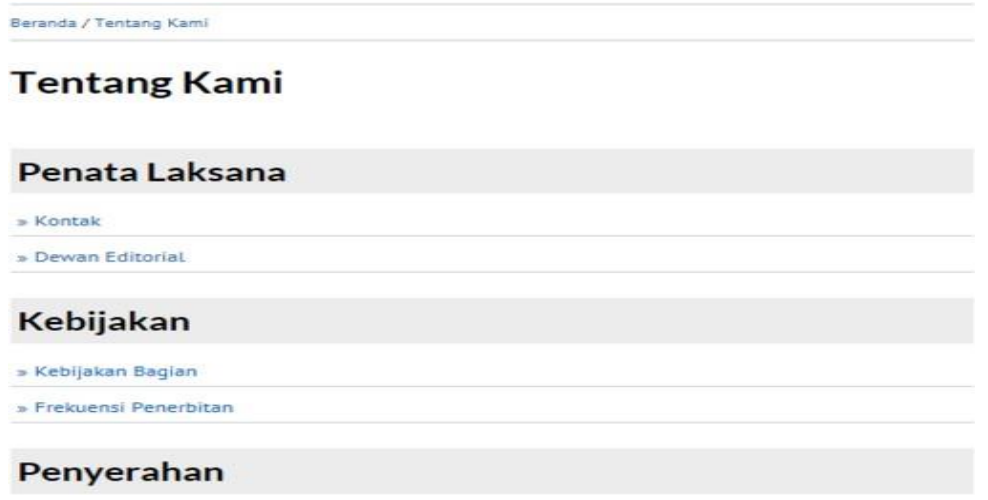

Gambar 5. Tampilan Menu Tentang Kami

(Sumber : http://ijc.ilearning.co/index.php/mozaik) 
Pada gambar 5 berikut merupakan halaman yang ada di website jurnal STISIP YUPPENTEK yang terdiri dari tampilan informasi penata laksana, kebijakan, penyerahan dan lain sebagainya.

\subsubsection{Tampilan Menu Admin}

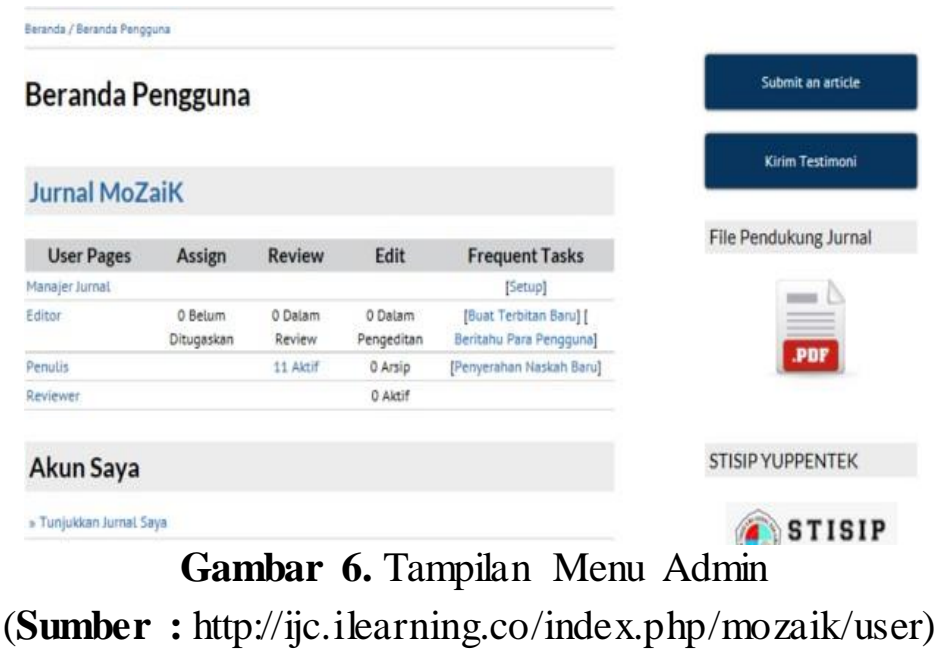

Pada gambar 6 berikut merupakan tampilan dari beranda Admin dimana pada bagian seluruh akses pada sistem ditampilkan mulai dari jurnal-jurnal yang ada dan hak akses didalamnya serta halaman administrasi situs yang kurang lebih fungsinya adalah sebagai configurasi sistem dimana bagian ini hanya akan tampil pada beranda Admin. Kemudian pada halaman ini juga nantinya akan ditampilkan akses-akses yang dapat digunakan oleh pengguna dimana dapat dilihat pada gambar diatas bahwa terdapat beberapa peran dengan dengan hak akses berbeda beda sesuai dengan hak akses yang dimiliki akun tersebut.

\subsubsection{Tampilan Menu Penulis}

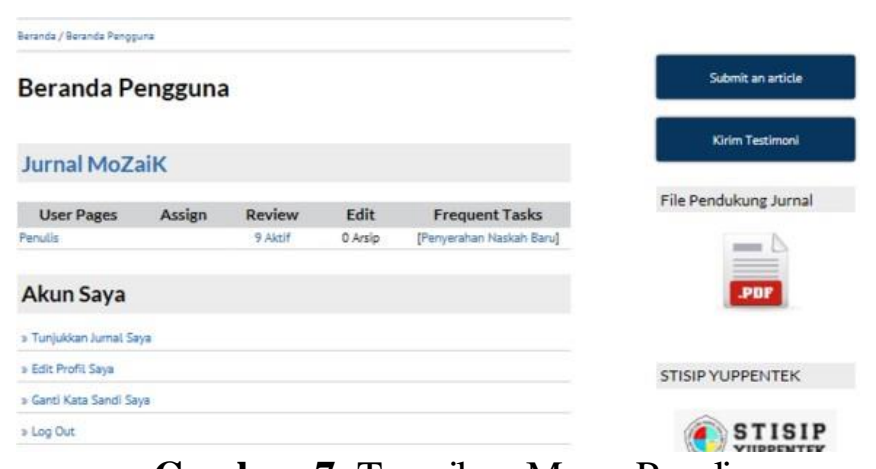

Gambar 7. Tampilan Menu Penulis

(Sumber : http://ijc.ilearning.co/index.php/mozaik/user) 
Pada gambar 7 berikut merupakan tampilan dari beranda penulis yang pada gambar diatas dapat dilihat bahwa seorang penulis memiliki satu fungsi utama yaitu melakukan penyerahan naskah (pada dasarnya semua akun yang terdaftar harus memiliki akses sebagai Penulis). Pada saat penulis melakukan penyerahan naskah nantinya dapat memonitoring artikelnya secara langsung pada bagian Review diamana nantinya akan terdapat link 1 naskah aktif atau lebih yang jika diakses akan mengantarkan penulis kehalaman review artikelnya.

\section{KESIMPULAN}

Sekolah Tinggi Ilmu Sosial dan Ilmu Politik YUPPENTEK di dalam pengelolaan karya ilmiah di STISIP YUPPENTEK ini masih manual atau masih bersifat konvensional yang diterapkan masih (tercetak) sehingga memiliki permasalahan-permasalahan seperti sistem pengelolaan jurnal yang cukup susah dan data terpisah-pisah karena memerlukan waktu yang lumayan lama dan biaya yang lumayan besar. Jurnal di STISIP YUPPENTEK belum dapat memenuhi syarat ketentuan Dikti tentang Akreditasi Jurnal yang mengharuskan sebuah jurnal dapat dikelola dengan cara elektronik agar dalam pengelolaan yang dilakukan lebih mudah dan cepat. dimana semua dalam proses pengelolaan yang dilakukan, yaitu proses pengiriman artikel, proses penyuntingan, penelaahan, dan penerbitan naskah karya ilmiah dilaksanakan secara online dalam satu sistem aplikasi yang disebut terbitan berkala ilmiah elektronik (e-journal).

Dengan adanya sistem e-journal pada STISIP YUPPENTEK dapat memudahkan bagi pengguna dalam submit jurnalnya dengan lebih mudah, cepat, hewat waktu, hemat biaya serta hemat tenaga. Menggunakan iJC dapat merubah pengelolaan e-journal menjadi lebih berdistribusi. Sehingga semua proses penyerahan naskah, mereview, mengedit, hingga mempublikasi semua dapat dengan mudah. Sehingga dapat menghasilkan sebuah jurnal online atau e-journal yang berkualitas.

\section{SARAN}

Kemudian berdasarkan semua yang sudah diteliti maka penulis memberikan beberapa saran yang kiranya dapat diadikan pertimbangan untuk mengembangkan bahkan meningkatkan pengelolaan dari jurnal yang telah ada pada Perguruan Tinggi.Terdapat 3 (tiga) saram diantaranya :

1. Perlu adanya sebuah sistem e-journal yang sistematis dan fleksibel sehingga sangat diminati para mahasiswa yang kreatif dengan tulisan-tulisan ilmiah.

2. Perlu adanya sebuah sistem yang dapat memberikan kemudahan bagi pengguna atau user dalam membuat suatu artikel ilmiah yang dapat berperan dalam proses pengelolaan jurnal dan proses tersebut dapat berjalan dengan lebih mudah dan efisien.

3. Karena semua Perguruan Tinggi diwajibkan memiliki E-Journal sebagai syarat Dikti untuk memenuhi ketentuan perihal Akreditasi Jurnal. 


\section{DAFTAR PUSTAKA}

[1] Tiara, K., Nurhaeni, T., \& amalia, I. (2016). Penerapan Viewboard GO+ Berbasis Yii Sebagai Media Monitoring Pembayaran Mahasiswa. Technomedia Journal, 1(1), 65-77. Diambil dari http:/ijc.ilearning.co/index.php/TMJ/article/view/17/13

[2] Rahardja, U., Handayani, I., \& Setiani, L. (2017). Viewboard Sebagai Laporan Jumlah Keseluruhan Artikel Pada iLearning Raharja Ask and News. CogITo Smart Journal, 3(1), 42-55.

[4] Thwari, Amit S. dan Dr. S.E Yedey.2016.Study Of Codeigniter Technology. International Journal of Research in Computer \& Information Technology. Vol. 2 No.2.

[5] Lee, Sunguk. 2012. Unified Modeling Language (UML) for Database Systems and Computer Applications. International Journal of Database Theory and Application. Vol.5 No.1.

[6] Soemantri, Nursam. 2015 Perancangan Viewboard iDuHelp! Menggunakan Bootstrap Sebagai Penunjang Laporan Perfoma iDuHelp! Online Pada Perguruan Tinggi.

[7] Amalia, Ika. 2016 Perancangan Viewboard GO+ Sebagai Penunjang Laporan Pembayaran Mahasiswa Pada Perguruan Tinggi

[8] Karalli, Rusol., Joyce Tipton Doina Dumitru., Lisa Scholz., Santhi Masilamani. 2015. Development of a metrics dashboard for monitoring involvement in the Drug Pricing Program, s.a. American Journal of Health-System Pharmacy September 1, 2015 vol. 72 no. 17 1489-1495.

[9] Damayanti, Isma . 2015. Analisa Perancangan Sistem Viewboard Zorilia dengan Menggunakan Metode Gamification Studi Kasus: Perguran Tinggi Raharja

[10] Christer-Nilsson, Carl. 2015. User Centered Design of a Monitoring Dashboard For Better Energy Performance. Sweden : CHALMERS UNIVERSITY OF TECHNOLOGY 